\title{
Perbandingan Penggunaan Jarum Sudut Tumpul dengan Jarum Tuohy untuk Transversus Abdominis Plane Block terhadap Penyebaran Anestetik Lokal pada Operasi Ginekologi
}

\author{
Aris Darmoko, ${ }^{1}$ Dedi Fitri Yadi, ${ }^{2}$ Tinni Trihartini Maskoen ${ }^{2}$ \\ ${ }^{1}$ Bagian Yanmed (Pelayanan Medik) Rumah Sakit Al-Islam Bandung \\ ${ }^{2}$ Departemen Anestesiologi dan Terapi intensif \\ Fakultas Kedokteran Universitas Padjadjaran/Rumah Sakit Dr. Hasan Sadikin Bandung
}

\begin{abstract}
Abstrak
Transversus abdominis plane block (TAPB) merupakan salah satu teknikanestesia regional untuk memblokade nyeri saat dilakukan sayatan kulit di dinding abdomen. Penelitian ini bertujuan membandingkan penggunaan jarum sudut tumpul dengan jarum tuohy untuk TAPB terhadap penyebaran anestetik lokal pada operasi ginekologi. Jenis penelitian eksperimental dengan uji acak terkontrol buta tunggal dilakukan di Rumah Sakit Dr. Hasan Sadikin Bandung periode Juli-Agustus 2014. Penelitian ini dilakukan terhadap 30 wanita berusia 18-60 tahun dengan status fisik American Society of Anesthesiologists (ASA) I-II yang menjalani operasi ginekologi dalam anestesi umum. Penelitian ini dibagi menjadi dua kelompok yaitu jarum sudut tumpul dan jarum tuohy. Teknik TAPB dilakukan di kedua sisiabdomen menggunakan $20 \mathrm{~mL}$ bupivakain 0,125\%. Sebelum dan sesudah TAPB dilakukan pencitraan ultrasonografi untuk membandingkan penyebaran anestetik lokal. Analisis statistika menggunakan Uji Mann-Whitney dan uji Z. Hasil penelitian ini menunjukkan penyebaran anestetik lokal pada kelompok jarum sudut tumpul 50\% dan pada kelompok jarum tuohy $26,7 \%$ secara statistika berbeda bermakna $(\mathrm{p}<0,05)$. Simpulan, pada operasi ginekologi dengan teknik TAPB penggunaan jarum sudut tumpul lebih baik dibanding dengan jarum tuohy terhadap penyebaran anestetik lokal.
\end{abstract}

Kata kunci: Jarum tuohy, jarum sudut tumpul, penyebaran anestetik lokal, transversus abdominis plane block

\section{Comparison between Short Bevel Needle and Tuohy Needle Use in Transversus Abdominis Plane Block on Local Anesthetic Spread During Gynecological Surgeries}

\begin{abstract}
Tranversus abdominis plane block (TAPB) is one of the regional anesthesia techniques which enable multimodal analgesia involving skin incision in abdominal wall. This study aimed to compare the use of short bevel needle and tuohy needle for TAPB on the spread of local anesthetics in gynecological surgeries through a experimental randomized single blind trial. This study was conducted in Dr. Hasan Sadikin General Hospital Bandung on July-August 2014 to 30 woman between 18-60 years with the American Society of Anesthesiologists (ASA) physical status I-II underwent gynecological surgery under general anesthesia. The subjects were divided into 2 groups, short bevel needle and tuohy needle groups. The block was given on both sides of the abdomen using $20 \mathrm{~mL}$ of bupivacaine $0.125 \%$. Before and after TAPB, an ultrasonography was performed to assess the spread of local anesthetics. Mann Whitney and Z test were used for statistical analysis. The results showed the spread of local anesthetic with short bevel needle was $50 \%$, and with tuohy needle was $26.7 \%$, the difference based on statistical analysis was significant $(p<0.05)$. In conclusions, the use of dull angle needle is better than tuohy needle in the spread of local anesthetics in TAPB in patients undergo gynecological surgeries.
\end{abstract}

Key words: Local anesthetic spreading, transversus abdominis plane block, short bevel needle, tuohy needle Korespondensi: Aris Darmoko, dr., SpAn, Bagian Yanmed (Pelayanan Medik) Rumah Sakit Al-Islam Bandung, Jl. Soekarno Hatta No. 6444, Telp. 022-7510585, Mobile 081931122975, Email aris_sajidfaqih@yahoo.co.id 


\section{Pendahuluan}

Penanganan nyeri pascaoperasi yang tidak adekuat dapat mengakibatkan efek samping, hal ini meningkatkan angka morbiditas dan juga mortalitas sehingga akan memperlambat penyembuhan dan aktivitas kembali menjadi normal. Tujuan penanganan nyeri pascabedah adalah memulihkan fungsi organ secara cepat, menghindari komplikasi, memberikan kenyamanan dan kepuasan pasien, mobilisasi lebih cepat, mempercepat penyembuhan, dan mengurangi biaya perawatan di rumah sakit., ${ }^{1,2}$

Penanganan nyeri dapat dilakukan secara farmakologi dengan memberikan analgetik atau nonfarmakologi melalui teknik mekanik, elektrik, dan psikologi. Sampai dengan saat ini para ahli masih terus mencari jenis analgetik yang lebih baik dengan efek samping minimal, aman, dan mudah dipergunakan. ${ }^{3}$

Anestesia regional semakin berkembang serta meluas pemakaiannya di seluruh dunia. Anestesia regional dapat memblokade organ spesifik, mempunyai durasi yang lama, serta dapat memberikan analgesi dan anestesia yang efektif. Anestesia regional dapat mengurangi nyeri dan juga efek samping mual dan muntah pascaoperasi sehingga dapat meningkatkan kepuasan serta mobilisasi yang lebih awal dan menghemat biaya perawatan pasien. ${ }^{4}$

Salah satu komponen nyeri yang dirasakan oleh pasien setelah operasi abdomen adalah bekas sayatan pada kulit dinding abdomen. Pendekatan pemberian analgesi pascaoperasi pada saat setelah sayatan abdominal adalah blokade saraf sensoris yang mensarafi dinding abdomen anterior. ${ }^{5}$

Transverse abdominis plane block (TAPB) diperkenalkan pada tahun 2001 untuk operasi abdomen yang memberikan anestesia dengan memblokade saraf interkostal torakal enam sampai sebelas saraf subkostal torakal 12 dan saraf ilioinguinal, serta saraf iliohipogastrik lumbal 1 dan lumbal 2. Teknik ini berkembang dengan teknik panduan anatomi dan panduan ultrasonografi. ${ }^{6}$

Segitiga Petit merupakan titik antara arkus kostarum dan krista iliaka yang sejajar dengan garis midaksilaris dan subkosta merupakan area penanda anatomi tempat penyuntikan ke dalam transverse abdominal plane (TAP). ${ }^{6,7}$ TAP adalah ruang antara musculus obliqus internus (MOI) dan musculus transversus abdominis (MTA) yang merupakan tempat berkumpulnya saraf torakal enam sampai lumbal satu. Lapisan dinding abdomen dari bagian permukaan sampai dengan bagian dalam dibentuk oleh kulit, jaringan subkutaneus, musculus obliqus externus (MOE), musculus obliqus internus (MOI), serta musculus transversus abdominis (MTA). ${ }^{7}$

Teknik penyuntikan ke TAP dengan metode "single poptechnique" telah diperkenalkan pada tahun 2001, kemudian dimodifikasi menjadi metode "double pop technique" memakai jarum anestesi regional yang disuntikkan tegak lurus dengan kulit. Hambatan atau "pop" pertama didapatkan saat jarum berada antara MOE dan MOI, sedangkan hambatan atau "pop" kedua didapatkan saat jarum berada di antara MOI dan MTA yang merupakan lokasi penimbunan anestetik lokal. ${ }^{5}$

Beberapa tipe jarum yang dapat digunakan untuk blokade pada TAP seperti Whitacre atau Sprotte 22G, tuohy 18G, dan Stimuplex 21G. Jarum tuohy dapat juga dipergunakan sebagai alat untuk memasukkan kateter pada blokade TAP sehingga pemberian anestetik lokal dapat diberikan secara terus menerus untuk memberikan efek analgesi pada dinding abdomen. ${ }^{8}$ Jarum yang dipergunakan untuk teknik regional biasanya telah dimodifikasi dari jarum suntik standar. Teknik blokade saraf perifer sekali suntik umumnya membutuhkan jarum sudut tumpul 22G sampai 24G. Jarum tuohy dengan ujung jarum tumpul sering dipergunakan untuk blokade saraf perifer yang diberikan terus menerus. Jarum sudut tumpul dan jarum tuohy dirancang untuk merasakan hambatan atau "pop" saat melewati jaringan yang berbeda. ${ }^{4}$

Melakukan anestesia regional berdasarkan pada panduan anatomi memunculkan 2 (dua) permasalahan yang penting. Pertama adalah ketepatan penempatan jarum dan penyebaran anestetik lokal pada target blokade saraf dan kedua adalah potensi kerusakan pada jaringan akibat penempatan jarum pada teknik anestesi 
regional panduan secara anatomi. ${ }^{9}$ Penelitian ini bertujuan menganalisis perbandingan penggunaan jarum sudut tumpul dengan jarum tuohy untuk transversus abdominis plane block terhadap penyebaran obat anestesi lokal pada operasi ginekologi.

\section{Subjek dan Metode}

Metode penelitian yang dipergunakan adalah penelitian eksperimen dengan rancangan uji klinis secara acak terkontrol buta tunggal. Teknik pengambilan sampel pada penelitian ini menggunakan consecutive admission (sesuai kedatangan pasien) dengan alokasi subjek ke dalam perlakuan dilakukan secara simple random sampling. Ukuran sampel ditentukan dengan menggunakan rumus uji dua proporsi. Dari rumus itu diperoleh jumlah sampel adalah 30 untuk tiap kelompok perlakuan, namun karena setiap orang dilakukan dua perlakuan maka jumlah sampel diambil 15 orang tiap kelompok penelitian sehingga jumlah sampel tiap kelompoknya adalah 15 orang dan jumlah seluruh sampel adalah 30 orang.

Penelitian dilakukan di Central Operating Theatre (COT) Rumah Sakit Dr. Hasan Sadikin Bandung periode Juli-Agustus 2014. Kriteria inklusi yaitu usia 18 sampai 60 tahun, operasi ginekologi, serta status fisik American Society of Anesthesiologists (ASA) I-II. Kriteria eksklusi yaitu pasien dengan body mass index (BMI) lebih dari $30 \mathrm{~kg} / \mathrm{m}^{2}$, infeksi kulit di dinding abdomen tempat suntikan TAPB, dan kelainan anatomi dinding abdomen tempat suntikan seperti jaringan parut.

Setelah mendapat persetujuan dari Komite Etik Penelitian Kesehatan Fakultas Kedokteran Universitas Padjadjaran/Rumah Sakit Dr. Hasan Sadikin Bandung, dilakukan penjelasan kepada subjek penelitian mengenai penelitian tersebut dan menandatangani persetujuannya (informed consent). Randomisasi dilakukan pada sampel menjadi dua kelompok perlakuan. Pada saat di ruang operasi dipasang kateter intravena, alat untuk mengukur tekanan darah noninvasif, elekrokardiografi (EKG), dan pulse oxymetri.

Semua pasien dilakukan anestesia umum dengan fentanil $2 \mu \mathrm{g} / \mathrm{kgBB}$, propofol $2-2,5$ $\mathrm{mg} / \mathrm{kgBB}$, serta atrakurium $0,5 / \mathrm{kgBB}$ secara intravena, setelah onset tercapai dilakukan intubasi. Setelah intubasi, dilakukan pencitraan ultrasonografi di kedua sisi abdomen untuk memberikan sebuah gambaran awal mengenai anatomi dinding abdomen. Proses selanjutnya, pada kelompok pertama dilakukan TAPB dan panduan anatomi di titik antara krista iliaka dan arkus kostarum sejajar linea midaksilaris mempergunakan jarum sudut tumpul dengan teknik penyuntikan "double pop". Kelompok kedua mendapatkan TAPB dengan panduan anatomi di titik antara krista iliaka dan arkus kostarum yang berada sejajar linea midaksilaris mempergunakan jarum tuohy dengan cara teknik penyuntikan "double pop". Penyuntikan anestetik lokal pada TAPB dilakukan di kedua sisi abdomen sehingga satu subjek penelitian akan tercatat dua buah penilaian penyebaran anestetik lokal. Kedua kelompok penelitian diberikan sebanyak $20 \mathrm{~mL}$ bupivakain $0,125 \%$ di setiap sisi abdomen. TAPB dilakukan oleh dua dokter spesialis anestesi dan seorang residen anestesi yang sudah dilatih melakukan TAPB. Setelah dilakukan TAPB dengan menggunakan panduan anatomi, kedua kelompok tersebut dilakukan pencitraan ultrasonografi untuk melihat penyebaran anestetik lokal di dinding abdomen. Kemudian, dilakukan perbandingan persentase pada penyebaran anestetik lokal sesuai dengan zona yang telah dibuat dan juga dilakukan uji statistika. Definisi variabel operasional pada penelitian ini, yaitu zona I adalah musculus obliqus externus (MOE), zona II adalah daerah interfasia antara fascia musculus obliqus externus (MOE) dan fascia musculus obliqus internus (MOI), zona III adalah musculus obliqus internus (MOI), zona IV adalah daerah interfasia antara fascia musculus obliqus internus (MOI) dan fascia musculus transversus abdominis (MTA), dan zona $\mathrm{V}$ adalah musculus transversus abdominis (MTA). Untuk membandingkan penyebaran anestetik lokal dikelompokkan menjadi dua kelompok: (1) zona benar adalah zona dengan penyebaran anestetik lokal pada pencitraan ultrasonografi yang melibatkan zona IV (zona 
Tabel 1 Karakteristik Umum Subjek Penelitian Kedua kelompok Perlakuan

\begin{tabular}{lccc}
\hline Karakteristik Respoden & \multicolumn{2}{c}{ Kelompok TAPB Jarum } & \multirow{2}{*}{ Nilai p } \\
\cline { 2 - 3 } & $\begin{array}{c}\text { Sudut Tumpul } \\
(\mathbf{n = 1 5})\end{array}$ & $\begin{array}{c}\text { Tuohy } \\
\text { (n=15) }\end{array}$ & \\
\hline Usia (tahun) & & & \\
Rata-rata (SD) & $42,20(6,58)$ & $41,87(10,47)$ & 0,838 \\
Rentang & $27-51$ & $18-59$ & \\
Berat badan (kg) & & & \multirow{2}{*}{0,744} \\
Rata-rata (SD) & $56.93(5,27)$ & $58,40(8,33)$ & \\
Rentang & $45-65$ & $45-70$ & \\
BMI (kg/m $\left.{ }^{2}\right)$ & & & 0,486 \\
Rata-rata (SD) & $23,39(2,32)$ & $24,18(2,70)$ & \\
Rentang & $18,73-26,84$ & $20,27-29,14$ & \\
\hline
\end{tabular}

Keterangan: nilai $\mathrm{p}^{*}$ berdasarkan Uji Mann-Whitney. Nilai p bermakna $(\mathrm{p}<0,05)$

III-IV dan zona IV-V), (2) zona salah adalah zona dengan penyebaran anestesi lokal pada pencitraan ultrasonografi tidak melibatkan zona IV (zona I, II, III, dan V).

Pemeliharaan anestesia dilakukan memakai isofluran serta $\mathrm{N}_{2} \mathrm{O}: \mathrm{O}_{2} 50 \%$. Tiga puluh menit sebelum operasi selesai diberikan analgetik intravena ketorolak $0,5 \mathrm{mg} / \mathrm{kgBB}$. Analgetik pascaoperasi diberikan melalui infus kontinu tramadol $2 \mathrm{mg} / \mathrm{kgBB}$ dan ketorolak $0,5 \mathrm{mg} /$ kgBB dalam Ringer laktat (RL) 500 mL dengan kecepatan 15 tetesan setiap menit. Setelah pasien diekstubasi lalu pasien dipindahkan ke ruang pemulihan. Analisis statistika data hasil penelitian mempergunakan Uji Mann-Whitney dan uji Z (menguji dua buah proporsi).

\section{Hasil}

Karakteristik umum subjek penelitian menurut usia, berat badan, serta body mass index (BMI) tidak terdapat perbedaan bermakna $(\mathrm{p}<0,05$; Tabel 1).

Pada penelitian ini, penyebaran anestetik lokal pada TAPB dengan panduan anatomi menggunakan jarum sudut tumpul dilakukan

Tabel 2 Penyebaran Anestetik Lokal Hasil Pencitraan Ultrasonografi pada Kelompok TAPB Jarum Sudut Tumpul dan Kelompok TAPB Jarum Tuohy

\begin{tabular}{lcc}
\hline \multicolumn{1}{c}{$\begin{array}{c}\text { Penyebaran } \\
\text { Anestetik Lokal }\end{array}$} & \multicolumn{2}{c}{ Kelompok } \\
\cline { 2 - 3 } & $\begin{array}{c}\text { TAPB Sudut Tumpul } \\
\text { (30 Penyuntikan) }\end{array}$ & $\begin{array}{c}\text { TAPB Jarum Tuohy } \\
\text { (30 Penyuntikan) }\end{array}$ \\
\hline Zona I & 1 & 0 \\
Zona I-II & 2 & 1 \\
Zona II & 1 & 1 \\
Zona II-III & 1 & 1 \\
Zona III & 7 & 16 \\
Zona III-IV & 7 & 5 \\
Zona IV & 7 & 2 \\
Zona IV-V & 1 & 1 \\
Zona V & 3 & 3 \\
\hline
\end{tabular}

Keterangan: Zona I adalah musculus obliqus externus, zona II adalah daerah interfasia antara fascia musculus obliqus externus dan fascia musculus obliqus internus, zona III adalah musculus obliqus internus, zona IV adalah daerah interfasia antara fascia musculus obliqus internus dan fascia musculus transversus abdominis, zona $\mathrm{V}$ adalah musculus transversus abdominis. Zona IV adalah daerah yang tepat untuk penyebaran anestetik lokal 
Tabel 3 Perbandingan Penyebaran Anestetik Lokal pada TAPB Menggunakan Jarum Sudut Tumpul dan Jarum Tuohy

\begin{tabular}{lccccc}
\hline \multirow{2}{*}{ Penyebaran Anestetik Lokal } & \multicolumn{2}{c}{ Kelompok Jarum } & \multirow{2}{*}{ Z } & \multirow{2}{*}{ Nilai p } \\
\cline { 2 - 3 } & Sudut Tumpul & Tuohy & & \multirow{2}{*}{15056} & \multirow{2}{*}{0,032} \\
\hline Zona benar & 15 & 8 & \\
Zona salah & 15 & 22 & & \\
\hline
\end{tabular}

Keterangan: nilai $p$ berdasarkan uji Z. Nilai p bermakna $(p<0,05)$

30 penyuntikan menggunakan jarum sudut tumpul 22G ukuran $50 \mathrm{~mm}$ dengan $20 \mathrm{~mL}$ bupivakain $0,125 \%$ yang disuntikkan di garis tengah antara arkus kostarum dan krista iliaka sejajar garis midaksilaris. Penempatan anestetik lokal pada zona benar yaitu zona IV terdapat 7 penyuntikan, zona III-IV terdapat 7 penyuntikan, serta zona IV-V terdapat 1 penyuntikan dari 30 penyuntikan (Tabel 2).

Penyebaran anestetik lokal TAPB dengan panduan anatomi menggunakan jarum tuohy dilakukan 30 penyuntikan dengan jarum tuohy 18G $80 \mathrm{~mm}$ dengan $20 \mathrm{~mL}$ bupivakain 0,125\% yang disuntikkan di garis tengah antara arkus kostarum dan krista iliaka yang sejajar garis midaksilaris. Penempatan anestetik lokal pada zona benar, yaitu zona IV dua penyuntikan, zona III-IV lima penyuntikan, dan zona IV-V satu penyuntikan dari 30 penyuntikan (Tabel 2).

Pada 30 penyuntikan menggunakan jarum sudut tumpul terdapat 15 penyuntikan yang penyebaran anestetik lokal berada pada zona benar dan sisa penyebaran anestetik lokal lain berada pada zona salah. Pada 30 penyuntikan memakai jarum tuohy terdapat 8 penyuntikan yang penyebaran anestetik lokalnya berada pada zona benar dan sisa yang lainnya berada pada zona salah. Berdasarkan uji Z, pada hasil perhitungan uji statistika terdapat perbedaan antara penyebaran anestetik lokal pada TAPB menggunakan jarum sudut tumpul dan jarum tuohy ( $p<0,05$; Tabel 3).

\section{Pembahasan}

Hasil analisis statistika menunjukkan bahwa karakteristik umum subjek penelitian kedua kelompok perlakuan tidak terdapat perbedaan bermakna $(p>0,05)$ sehingga kedua kelompok dianggap homogen serta dapat dibandingkan. Rencana awal penelitian ini akan dilakukan TAPB dengan panduan anatomi melalui suatu segitiga Petit, namun terdapat kesulitan dalam melakukan penyuntikan TAPB karena posisi segitiga Petit berada lebih posterior dibanding dengan garis midaksilaris dan kesulitan saat melakukan pencitraan ultrasonografi.

Segitiga Petit merupakan area anatomi yang merupakan daerah penyuntikan ke dalam TAP. Dasar segitiga Petit dari bagian permukaan sampai bagian dalam dibentuk oleh jaringan subkutaneus, musculus obliqus internus (MOI), dan juga musculus transversus abdominis (MTA). Pada sebuah penelitian 26 kadaver mengenai anatomi segitiga Petit didapatkan bahwa segitiga Petit terletak lebih posterior dari literatur yang disarankan. Segitiga Petit mempunyai variasi posisi lebar dan ukurannya relatif kecil dan juga tidak semua target saraf berada di daerah ini. ${ }^{7,9}$ Pendekatan anterior memakai titik tengah antara arkus kostarum dan krista iliaka di garis midaksilaris lebih optimal dalam pencitraan ultrasonografi dan semua persarafan abdominal berada di daerah ini. ${ }^{7,9-11}$

Hasil penyuntikan pada kedua kelompok penelitian ternyata keberhasilan penyebaran anestetik lokal masih rendah. Pada kelompok TAPB jarum sudut tumpul sebanyak 15/30, sedangkan pada kelompok TAPB jarum tuohy sebanyak 8/30. Keberhasilan teknik TAPB dengan panduan penanda anatomi oleh para tenaga ahli yang berpengalaman sekitar $85 \%{ }^{5}$ Sebuah penelitian terhadap 36 pasien dewasa yang menjalani operasi kebidanan diberikan TAPB dengan panduan anatomi melalui titik tengah antara krista iliaka dan batas kosta di 
garis midaksilaris menggunakan jarum sudut tumpul 21G dengan anestetik lokal bupivakain $0,25 \%$ sebanyak $20 \mathrm{~mL}$ di setiap sisi dinding abdomen. Pencitraan ultrasonografi dilakukan sebelum dan sesaat dilakukannya TAPB, lalu dinilai penyebaran anestetik lokal dan letak jarum.

Berdasarkan pada hasil penelitian tersebut didapatkan bahwa penempatan jarum serta anestetik lokal yang tepat hanya 17 , jaringan subkutan satu, MOE satu, antara MOE dan MOI lima, MOI 26, MTA sembilan dan peritoneum 13. Dari 72 penyuntikan, 32 dilakukan oleh konsultan dan 40 oleh traine. Sebanyak 15 penyuntikan atau $46 \%$ yang disuntikkan oleh konsultan dan 2 penyuntikan atau 5\% yang disuntikkan oleh traine berada pada tempat yang benar. Penyuntikan ke dalam peritoneal dilakukan oleh traine sebanyak 13 atau 33\%, sedangkan oleh konsultan tidak ada. Peneliti menyimpulkan bahwa penempatan jarum dan anestetik lokal pada TAPB dengan panduan anatomi tidak tepat. ${ }^{9}$ Empat penelitian (172 pasien) mengenai TAPB dengan penanda anatomi tidak melaporkan komplikasi dari TAPB. ${ }^{5,9,12}$

Hasil dari analisis statistika menunjukkan bahwa untuk penyebaran anestesi lokal pada kedua kelompok perlakuan berbeda bermakna $(\mathrm{p}<0,05)$. Penyebaran anestetik lokal pada kelompok TAPB jarum sudut tumpul lebih baik dibanding dengan kelompok TAPB jarum tuohy.

Pada blokade saraf perifer sangat penting untuk memahami teknik loss of resistance (LOR). Teknik LOR menggunakan jarum sudut tumpul terbukti baik menghasilkan hambatan atau "pop" pada saat melalui fasia. ${ }^{13}$ Blokade saraf perifer dengan struktur yang dalam atau pasien yang gemuk baik jarum tuohy ataupun jarum spinal pencil point 22G dapat dipergunakan. Meskipun teknik ini sederhana tetapi masih dapat terjadi kegagalan. Keadaan ini disebabkan tidak dapat merasakan "pop" atau hambatan terutama pada pasien obesitas karena lapisan fasia yang lemah dan menipis atau timbunan anestetik lokal yang berada di tempat salah yang merupakan alasan tersering pada kegagalan blokade saraf perifer. ${ }^{13}$
Pada penelitian tersebut terdapat beberapa kelemahan: pertama, TAPB dilakukan di garis midaksilaris, sedangkan di beberapa literatur segitiga Petit merupakan penanda anatomi yang disarankan. Kedua, pada penelitian ini jarum yang digunakan pada satu subjek penelitian menggunakan satu jarum untuk dua penyuntikan sehingga memengaruhi kualitas penyuntikan jarum di sisi abdomen lainnya. Ketiga, pada penelitian ini tidak melihat ujung jarum dan penyebaran secara langsung sehingga tidak dapat untuk membandingkan penyebaran anestetik lokal pada TAPB menggunakan jarum sudut tumpul dengan jarum tuohy.

\section{Simpulan}

Penggunaan jarum sudut tumpul lebih baik bila dibanding dengan jarum tuohy terhadap penyebaran anestetik lokal untuk transversus abdominis plane block panduan anatomi pada pasien operasi ginekologi.

\section{Daftar Pustaka}

1. Macres SM, More PG, Fishman SM. Acute pain management. Dalam: Barash PG, Cullen BF, Soelting RK, penyunting. Clinical anaesthesia. Edisi ke-6. Philadelphia: Lippincot Williams \& Wilkins; 2009. hlm. 1474-504.

2. Kehlet H, Holte K. Effect of postoperative analgesia on surgical outcome. $\mathrm{Br} \mathrm{J}$ Anaesth. 2001;87:62-72.

3. Lubenow $\mathrm{T}$, Ivankovich A, Barkin $\mathrm{R}$. Management of acute post-operative pain. Dalam: Barash PG, Soelting RK, penyunting. Clinical anesthesia. Edisi ke-5. Philadelphia: Lippincot William \& Wilkins; 2006. hlm. 1405-34.

4. Tsui BC, Rosenquist RW. Peripheral nerve blockade. Dalam: Barash PG, Cullen BF, Soelting, RK, penyunting. Clinical anesthesia. Edisi ke-6. Philadhelphia: Lippincot William \& Wilkins; 2009. hlm. 955-1002.

5. McDonnel JG, O’Donnel B, Heffernan A, Power C, Laffey JG. The analgesic efficacy 
of transversus abdominis plane block after abdominal surgery: a prospective randomized controlled. Anesth Analg. 2007;104:193-7.

6. Zhirajr M. Anatomy for anesthesiologists. Dalam: Zhirajr MGV, Costantini A, Fumagilli $\mathrm{R}$, penyunting. The flying publisher guide to ultrasound blocks for the anterior abdominal wall. Edisi ke-3. Monza: Flying Publisher; 2011.

7. Jankovic ZB, McConnel P. An anatomical study of the transversus abdominis plane block: location of the lumbar triangle of Petit and adjacent nerves. Anesth Analg. 2009;109(3):1-5.

8. Jankovic Z. Transversus abdominis plane block: the holy grail of anaesthesia for (lower) abdominal surgery. Periodicum Biologorium. 2009;111(2):203-8.

9. McDermott G, Korba E, Jaigirdar M, Narayanan N, Boylan J, Conlon N. Should we stop doing blind transversus abdominis planeblocks? Br J Anaeth. 2012;108(3):499-502.

10. Abdallah FW, Chan VW, Brull R. Transversus abdominis plane block a systematic review. Reg Anesth Pain Med. 2012 MarchApril;37(2):193-209.

11. Carney J, Finnerty O, Rauf J, Bergin D, Laffey JG, Mc Donnell JG. Studies on the spread of local anaesthetic solution in transversus abdominis plane blocks. Anaesthesia. 2011;66:1023-30.

12. Salman AE, Yetisir F, Yurekli B, Aksoy M, Ylldırım M, Kilıc M. The efficacy of the semiblind approach of transversus abdominis plane block on postoperative analgesia in patients undergoing inguinal hernia repair: a prospectiverandomized doubleblind study. Local Regional Anesthesia. 2013;6:1-7.

13. Singh SK, Kuruba SMG. The loss of resistance nerve blocks. ISRN Anesthesiol. 2011;2011:10. 